\title{
SITUAÇÃO ENUNCIATIVA EM PROVAS DE REDAÇÃO DO CONCURSO VESTIBULAR DA UNESPAR ${ }^{1}$
}

\author{
ENUNCIATIVE SITUATION IN WRITING ESSAY \\ EXAM FROM UNESPAR ADMISSION TEST
}

\author{
Adriana Beloti ${ }^{2}$ \\ Universidade Estadual do Paraná \\ Isabela de Pontes Mariano ${ }^{3}$ \\ Universidade Estadual do Paraná
}

\begin{abstract}
Resumo: O objetivo desta pesquisa é analisar os comandos de produção das Provas de Redação dos Concursos Vestibular (CV) da Unespar, de 2018/2019 e 2019/2020, quanto aos elementos das condições estabelecidas para a escrita dos textos pelos candidatos. Realizamos um estudo de natureza qualitativa, pautado nas pesquisas da linguagem em perspectiva enunciativo-discursiva e em Menegassi (2011) e Costa-Hübes (2012), acerca das condições de produção para a escrita. A análise é realizada por meio do caderno de provas do $\mathrm{CV}$, investigando os elementos que compõem as condições de produção. A partir dos resultados, contribuímos quanto à reflexão da adequação da Prova de Redação ao que se apresenta em documentos oficiais de vertente teóricometodológica discursiva para o ensino de Língua Portuguesa, além do aspecto relacionado à prática de escrita como conteúdo curricular dos Ensinos Fundamental e Médio.

Palavras-Chave: Vestibular; Redação; Encaminhamentos de produção textual; Condições de produção.

1 Este artigo é resultado de estudos realizados no Programa de Iniciação Científica da Unespar, com bolsa da Fundação Araucária do Paraná (2019-2020), e desenvolvido no interior do Grupo de Pesquisa PRÁDIS - Práticas Discursivas na Escola (Unespar/CNPq).

2 Endereço eletrônico: adriana.beloti@unespar.edu.br.

3 Endereço eletrônico: isabelapontesmariano99@gmail.com.
\end{abstract}




\begin{abstract}
The aim from this research is to analyze the production instructions about the writing essay exam from UNESPAR textual production directions, from years 2018/2019 and 2019/2020, regarding to condition elements established to the essay candidates to write their texts. We did an qualitative study, based on works about the enunciative-discursive perspective of language and in Menegassi (2011) and Costa-Hübes (2012) about the textual production conditions to write. The analysis was made in the essay textbooks, which we use to look for the elements that composed the production conditions. From the results, we contribute with the reflection about the writing essay exam adequation to what is presented in discursive theoretical-methodological perspective official documents to Portuguese teaching, besides the aspects related to writing practice as curricular content in Elementary and High school.
\end{abstract}

Keywords: College admission test; Essay; Textual production directions; Production conditions.

\title{
INTRODUÇÃO
}

Tanto na academia, quanto no interior de espaços escolares, as discussões acerca da produção de textos são constantes, especialmente, quando se trata de práticas relacionadas ao processo de ensino e aprendizagem na Educação Básica. No que se refere ao contexto de Concurso Vestibular (CV), instituído no Brasil em 1911, pelo Decreto n. $8659^{4}$, a prova de redação passou a ser obrigatória em 1977, conforme Decreto n. $79.298^{5}$, ocasionando estudos voltados a esse elemento do $\mathrm{CV}$ e, também, à relação de tal prova aos conteúdos curriculares dos Ensinos Fundamental e Médio. A Portaria n. 2.941/20016 do Ministério da Educação (MEC) estabeleceu a prova de redação como etapa eliminatória de todo processo seletivo para ingresso no Ensino Superior. Não obstante, é possível estabelecermos relação entre essas datas características de CV no Brasil a documentos oficiais que legislam acerca de práticas pedagógicas nas escolas e, ainda, a desdobramentos de perspectivas teórico-metodológicas.

4 Disponível em: <https://www2.camara.leg.br/legin/fed/decret/1910-1919/decreto-8659-5abril-1911-517247-publicacaooriginal-1-pe.html>. Acesso em: 11 jun. 2020.

5 Disponível em: <https://www2.camara.leg.br/legin/fed/decret/1970-1979/decreto-79298-24fevereiro-1977-428202-publicacaooriginal-1-pe.html>. Acesso em: 11 jun. 2020.

6 Disponível em: <http://estacio.br/ensinomedio/vestibularescola/docs/portariamec.pdf >. Acesso em: 11 jun. 2020. 
Nesse sentido, a partir da década de 80 e, mais destacadamente, posterior à Lei de Diretrizes e Bases da Educação - LDB n. 9394/967 -, não só os aspectos linguísticos e gramaticais das redações de candidatos a vagas no Ensino Superior foram estudados, mas, também, seus aspectos discursivos, dada a concepção interacionista de linguagem que marca o viés teórico-metodológico dessa legislação, de acordo com as afirmações de Zanini (1999). Historicamente, o foco dado à prova de redação em processos seletivos, seja em CV, ENEM (Exame Nacional do Ensino Médio) ou para admissão em vagas de emprego, é quanto ao tema solicitado, o que revela o subsídio na concepção de escrita como dom (SERCUNDES, 2004), ou seja, práticas a respeito de um tema informado no momento da execução da escrita, sem considerar qualquer conhecimento prévio do produtor do texto e/ou condições para que o texto seja escrito.

No entanto, a partir dos anos 2000, com o desenvolvimento de pesquisas na área da Linguística Aplicada, que consideraram estudos teóricos e metodológicos, bem como documentos oficiais, como os Parâmetros Curriculares Nacionais - PCN (BRASIL, 1998) -, as Diretrizes Curriculares Estaduais de Língua Portuguesa - DCE (PARANÁ, 2008) - e, mais recentemente, a Base Nacional Comum Curricular - BNCC (BRASIL, 2017) -, diversas universidades passaram a solicitar a produção de textos por meio de determinados gêneros textuais, extrapolando o padrão de textos dissertativo-argumentativos, como ainda é solicitado, por exemplo, no ENEM, para textos relativos a temáticas diversas e materializados por meio de gêneros variados e, devidamente, estabelecidos no comando de produção da prova de redação. Na esteira de tais mudanças, ainda que o tema permaneça como foco nos $\mathrm{CV}$, o gênero pedido, no caso de Instituições cujas provas são nesse viés, também passou a ter interesse,

7 Disponível em: <http://www.planalto.gov.br/ccivil_03/leis/19394.htm>. Acesso em: 11 jun. 2020. 
inclusive, nas aulas de Língua Portuguesa e nos cursinhos preparatórios para processos seletivos e de admissão.

O CV da Universidade Estadual do Paraná (Unespar), unificado entre seus sete campi desde 2014, seguindo os documentos oficiais relativos ao processo de ensino e aprendizagem e as pesquisas da Linguística Aplicada que se voltam ao estudo de práticas discursivas, especialmente, da prática de produção textual escrita, solicita em sua prova de redação a escrita de um gênero textual marcado no comando de produção.

Assim, considerando os objetos de análise: os encaminhamentos de produção da Prova de Redação dos CV da Unespar de 2018/2019 e 2019/2020, o objetivo deste trabalho é analisar os comandos quanto aos elementos das condições de produção (CPs), quais sejam: finalidade, interlocutor, gênero discursivo, suporte textual, circulação social, posição do autor e estratégias (MENEGASSI, 2011; COSTA-HÜBES, 2012), tomando o gênero em um de seus aspectos constituintes, a focalizar o conteúdo temático.

Para alcançar esse objetivo, então, pautamo-nos na perspectiva discursiva dos estudos da linguagem, originária da concepção sócio-histórica, cultural e ideológica de língua/linguagem, de acordo com Volóchinov (2019), já demarcando nossa compreensão dialógica, em sentido amplo, como as várias formas de materialização dos sujeitos, e, em sentido mais específico, no que se refere ao plano do trabalho com textos, em relação a situações de ensino. Nesse contexto, as propostas de Bakhtin ([1979] 1999) quanto à enunciação também são fundantes ao projeto de análise empreendido neste trabalho. Como aporte específico para as análises do corpus, tomamos o conceito de condições de produção, segundo Geraldi (1997), Menegassi (2011) e Costa-Hübes (2012). Avaliar a forma como a Prova é organizada torna-se relevante, pois investiga se está adequada à perspectiva discursiva de linguagem, cuja proposta é a que pauta o ensino de Língua Portuguesa e o trabalho de escrita nas escolas de 
Educação Básica, conforme demarcado pelos PCN (BRASIL, 1998) e BNCC (BRASIL, 2017), subsidiados em uma concepção discursiva de linguagem, ou seja, uma vertente interacionista de linguagem para o ensino de Língua Portuguesa (PERFEITO, 2010).

A pesquisa tem como ponto de partida resultados já apresentados nos trabalhos de Beloti e Luz (2019) e Luz e Beloti (2018), que tratam das Provas de Redação dos CV de 2014/2015 a 2017/2018. Assim, em uma proposta de estudo longitudinal e contínua, este artigo analisa os encaminhamentos da Prova de Redação dos últimos CV da Universidade, para que, além do objetivo específico relacionado ao conceito próprio da Linguística Aplicada, isto é, da análise dos elementos das condições de produção, possa cumprir, também, a função de subsidiar reflexões e avaliações, tanto da Unespar, em relação à adequação da Prova de Redação ao que se apresenta em documentos oficiais de vertente teórico-metodológica para o ensino de Língua Portuguesa, quanto a professores da Educação Básica que trabalham com a prática de escrita como conteúdo curricular. Logo, discute acerca de como a Universidade dialoga com o que há estabelecido para a Educação Básica, não com objetivo interno, mas marcando a relação do Ensino Superior com a escola.

Dentre os fatores que motivam esta pesquisa, relacionando CV e ensino na Educação Básica, destacamos, por exemplo, uma notícia publicada pelo site Brasil Escola8, em 2019, afirmando que "Mais de 143 mil participantes tiraram zero na Redação do ENEM" e apenas 53 candidatos atingiram a nota máxima na redação. Tal informação, aliada a diversas outras, comumente em circulação, a respeito da escrita e do desempenho de candidatos em provas seletivas e avaliativas, como concursos, vestibular e avaliação escolar, leva-nos a retomar e ampliar os resultados e reflexões relativas ao corpus desta pesquisa, por exemplo, avaliando

\footnotetext{
8 Disponível em: <https://vestibular.brasilescola.uol.com.br/enem/mais-143-mil-participantestiraram-zero-na-redacao-enem-2019/347183.html>. Acesso em: 11 jun. 2020.
} 
aspectos específicos da situação enunciativa estabelecida, considerada como determinante para a atuação dos sujeitos produtores do texto, pautados na tese de que os comandos de produção, tomados como encaminhamentos, apresentam todos os elementos necessários para dar condições aos candidatos, ou seja, delimitam finalidade, interlocutor, gênero discursivo, suporte textual, circulação e posicionamento social (MENEGASSI, 2011), além das estratégias para a escrita (COSTA-HÜBES, 2012), constantes em algumas propostas.

\section{ENUNCIAÇÃO E ENUNCIADO: AS CONDIÇÕES DE PRODUÇÃO TEXTUAL}

Pautados nos estudos da linguagem em perspectiva enunciativodiscursiva (VOLÓCHINOV, 2018), avaliamos que é tal teoria que nos possibilita compreender que o texto não é um produto, mas um processo, dadas as discussões a respeito de diversos conceitos relativos à linguagem, os quais levam à proposição do dialogismo, delineado do entendimento amplo de constante diálogo com o outro e, assim, como mecanismo inerente a toda e qualquer enunciação (BAKHTIN, [1979] 1999).

Além disso, essa concepção de língua/linguagem faz-nos compreendê-la como formas de materialização que proporciona a inter(ação) entre os sujeitos, e a escrita é uma das possibilidades de materializar tal ação. Portanto, a linguagem é um acontecimento sócio-histórico, cultural e ideológico, que existe pelas interações entre sujeitos, o que constitui o processo interlocutivo. A intersubjetividade constitui todas as práticas de linguagem e, então, é na interação verbal social que os sujeitos constituem-se e, também, é apenas em tais situações que a língua/linguagem significa (VOLÓCHINOV, 2019).

A linguagem é, assim, o meio de materializar as relações dialógicas, em sentido mais amplo, estabelecidas em toda e qualquer situação enunciativa, ou seja, a materialidade da situação é chamada de enunciado, que carrega em si 
todos os elementos sociais, históricos, culturais e ideológicos daquele diálogo situado. Para tanto, recorre-se à palavra, que pode assumir diversas funções, de acordo com a situação interativa na qual se materializa e ganha vida. A palavra

[...] pode assumir qualquer função ideológica, dependendo da maneira em que aparece num enunciado concreto. Além disso, pode ser entendida como um "signo neutro", não no sentido de que não tenha "carga ideológica", mas no sentido de que, como signo, como conjunto de virtualidades disponíveis na língua, recebe carga significativa a cada momento de seu uso. (STELLA, 2012, p. 179)

Ao que nos propomos na pesquisa, consideramos a escrita como prática discursiva e, em situação pedagógica, podendo ser caracterizada como processo, se realizada em diversas etapas, conforme propõem Fiad e Mayrink-Sabinson (1991) e Menegassi (2016), ao tratarem do conceito de escrita como trabalho. Dessa forma, a palavra, ora assumida pelo professor - propositor da produção de texto -, ora pelo estudante - produtor do texto -, além de ambos em seus papéis na revisão e na reescrita, é alternada entre um e outro sujeito, carregando, além de suas constituições, as marcas típicas da situação na qual é usada, qual seja, das condições estabelecidas para a escrita de determinado texto. À vista desse viés para a compreensão da escrita, ilustramos a posição assumida a partir da relação entre os debates relativos à linguagem em nível mais filosófico, segundo Volóchinov (2018; 2019) e Bakthin ([1979] 1999), e no âmbito da Linguística Aplicada, quando estudada em situações próprias de ensino e aprendizagem, ratificando a predominância do social - externo - à constituição inerente da linguagem, "[...] produto da atividade coletiva humana, e todos os seus elementos refletem [e refratam] a organização tanto econômica quanto sociopolítica que a gerou" (VOLÓCHINOV, 2019, p. 248, grifos do autor).

Na realização da Prova de Redação do CV, há, também, parte da troca de turnos, ainda que não ocorram os processos de revisão e de reescrita do texto. A conjuntura inicial é estabelecida pela Instituição, que apresenta a proposta da 
Prova ao candidato; cumprida por este, que se assume como produtor do texto na enunciação delimitada, considerando-se, nesse caso, tanto os elementos das condições de produção, quanto o contexto social mais amplo, isto é, o cenário didatizado e hipotético criado para delinear uma situação enunciativa de escrita em CV; por fim, a avaliação do texto produzido marca o retorno da palavra à Universidade.

Logo, as Provas de Redação também cumprem o propósito interlocutivo da linguagem compreendida nesse viés enunciativo-discursivo e, portanto, pressupõe-se que, a partir de tal vertente, mesmo em contexto de $\mathrm{CV}$, no qual se estabelece uma situação enunciativa hipotética, se delimitem reais condições para que os candidatos escrevam, os quais, na linha dessa concepção, são concebidos como sujeitos sociais, históricos, culturais e ideológicos, que agem e se marcam por meio do texto escrito.

Menegassi (2011), ao estudar os elementos das CPs com fundamento na proposta do Círculo de Bakhtin, define seis aspectos a serem considerados em um comando de escrita: finalidade, interlocutor (em suas três possibilidades de constituição: real, virtual e superior), gênero discursivo, suporte textual, circulação social e posicionamento social do autor. Tais elementos visam a delimitar a situação enunciativa na qual o texto é escrito e à qual objetiva atender, constituindo condições para a produção adequada. Geraldi (1997) também propõe que, para a escrita de um texto, sejam definidos: o que, por que, para quem e como dizer, além do fato de que o produtor se assuma como tal. Ambos os autores indicam, portanto, a compreensão de que nenhum uso da linguagem é neutro ou que ocorra isolado do contexto sócio-histórico, cultural e ideológico que envolve os sujeitos interactantes do processo.

A finalidade de um texto, ou seja, o motivo pelo qual se escreve, é o primeiro elemento a ser estabelecido e, conforme Menegassi (2011, p. 103), “[...] é a partir dela que se tem a escrita de um texto que permite a formação e o 
desenvolvimento de sujeitos que se tornam autores do seu próprio discurso". É alicerçado na finalidade que o estudante constitui-se no projeto de dizer e tem como suporte e reflexão desenvolver-se socialmente por meio de uma fala/escrita; é por tal elemento que o sujeito materializa sua posição social a respeito de determinado tema, projetando-se como autor de sua própria fala, sem ser uma escrita decorada ou reproduzida. Logo, é a finalidade, que corresponde ao porquê se escreve (GERALDI, 1997), que dá início ao processo de produção do discurso, conforme a situação enunciativa específica, e estabelece os interlocutores para os quais o texto é produzido. De acordo com Menegassi (2003), na escola, é função do elaborador da proposta de escrita - professor ou material didático - delimitar a finalidade de determinada prática discursiva. Igualmente, no CV, independente a quem seja atribuída a função de elaborar a prova de redação, é de competência da Instituição promotora do processo marcar a finalidade de escrita da situação enunciativa estabelecida ${ }^{9}$, visto que este é o elemento que subsidia a prática.

O interlocutor do texto é para quem se dirige determinada produção, o discurso específico. É definido pela situação enunciativa e cumpre papel fundamental ao estabelecer o como (GERALDI, 1997) o texto é escrito, ou seja, demarcando o gênero discursivo, em todas as suas características, por exemplo, o estilo de linguagem a ser usado. Conforme a proposta de Bakhtin ([1979] 1999), o interlocutor é classificado em real, virtual e superior ${ }^{10}$. Em cenário de $\mathrm{CV}$, essa variedade de interlocutores materializa-se de maneira específica, pois a situação enunciativa, por mais que conte com todos os elementos para a produção de um discurso especificamente marcado em uma enunciação, configura-se como

\footnotetext{
9 Consideramos, fundamentados no aporte teórico-metodológico elegido para a pesquisa, a finalidade da situação enunciativa como divergente do objetivo do CV, qual seja: ser aprovado e ocupar uma vaga em curso de graduação oferecido pela Universidade.

10 O estudo de Menegassi e Fuza (2006) é, também, suporte às considerações relativas ao conceito de interlocutor que exemplificamos neste trabalho.
} 
hipotética, já que o texto do candidato, na prática, não circula efetivamente. Desse modo, a delimitação dos interlocutores, em todos os seus papéis, pode ser inferida. Para Carla Catarina Silva,

O interlocutor demarcado por meio de inferência não prejudica a composição do Comando, desde que se tratem de produções de gêneros escolares ou desde que, nos casos de solicitação de gêneros não escolares, as propostas tragam elementos das condições de produção suficientes para que não haja dúvidas quanto a quem se destina a produção. (SILVA, 2018, p. 99)

Comumente, o interlocutor virtual, delineado pela imagem construída pelo locutor no momento da enunciação, diz respeito ao sujeito para quem se escreve, cuja delimitação é feita no comando de escrita, é marcado na atividade de escrita, enquanto os outros dois modos, mais frequentemente, prescindem de inferência.

O interlocutor real é constituído ao ser delimitada a imagem do outro a quem se dirige o discurso. Esse interlocutor está presente fisicamente no momento da produção verbal e influencia diretamente tal produção, correspondendo, em situação pedagógica, geralmente, ao professor. O interlocutor superior é o responsável maior por orientar e determinar as regras e os padrões de produção do enunciado, o todo do corpo social a que pertence o produtor e, então, no contexto de ensino, refere-se à instituição escolar, que representa todo o conjunto social, histórico, cultural e ideológico que perpassa a produção do texto.

A fim de ilustrar essas possibilidades de interlocutores, apresentamos a seguir o Quadro 1, com a especificação dos interlocutores estabelecidos, de forma marcada ou não, nas propostas das Provas objeto de estudo, neste trabalho: 
Quadro 1: O interlocutor nos Comandos de Produção de 2018/2019 e 2019/2020

\begin{tabular}{|l|c|l|l|}
\hline \multicolumn{2}{|c|}{ ELEMENTO } & \multicolumn{1}{c|}{ 2018/2019 } & \multicolumn{1}{c|}{ 2019/2020 } \\
\hline \multirow{4}{*}{ Interlocutor } & Real & Professor & Professor \\
\cline { 2 - 4 } & Virtual & $\begin{array}{l}\text { Internautas do fórum de } \\
\text { discussão }\end{array}$ & $\begin{array}{l}\text { A própria instituição } \\
\text { (implícito) }\end{array}$ \\
\cline { 2 - 4 } & Superior & Instituição & Instituição \\
\hline
\end{tabular}

Fonte: Elaborado pelas autoras.

O conceito de gênero discursivo assentido por Bakhtin ([1979] 1999) considera o funcionamento da linguagem em práticas interativas, reais e concretas, que são arquitetadas por sujeitos que interagem entre si nas relações humanas e de interação verbal social. Assim, na Prova de Redação do CV, o gênero tem como objetivo colocar em funcionamento a prática de linguagem do candidato que, no cenário delimitado para a escrita, é requerido a assumir a posição social estabelecida. Ademais, é o que dá forma e cumpre a função social e comunicativa específica, entre o candidato e a Universidade, sendo que ambos, cada qual em seu turno, posicionam-se em relação ao plano materializado naquela enunciação: a Universidade, por meio da Prova; o candidato, em seu texto ${ }^{11}$.

Sendo assim, na Prova de Redação do CV da Unespar, como em outros contextos de produção de um texto, o gênero corresponde a um "modelo", mais ou menos estabilizado (BAKHTIN, [1979] 1999), já definido do texto que será produzido. É um texto, de certa forma, conhecido e que já circula na sociedade, cumprindo função de intermediar a interação do produtor com seus interlocutores. O gênero não se caracteriza, primeiramente, por aspectos estruturais e formais, mas, justamente, por sua finalidade e pelas funções sociais

11 Ainda que não seja objeto de estudo neste trabalho, consideramos pertinente registrar nossa proposição de que o posicionamento da Universidade, de certa forma, pode ser depreendido pelos textos que compõem o encaminhamento de produção textual, os chamados "textos de apoio". Como parte integrante de toda a proposta da Prova de Redação, tais textos e tal posicionamento exercem papel importante ao se tomar a orientação que o interlocutor superior desempenha no processo de produção do discurso escrito. 
e comunicativas que cumpre, de acordo com cada situação de interação verbal social, conforme as enunciações (BAKHTIN, [1979] 1999), ancorando-se aos campos de atividade humana que engendram discursos próprios e propícios a cada interação.

Cabe destacar que, dadas as especificidades da situação hipotética e avaliativa que perpassa a Prova de Redação do CV, nessa modalidade de uso da linguagem escrita, o que o comando da Prova solicita é a produção de gênero textual, em distinção ao conceito de gênero discursivo. Conforme Silva (2018, p. 43),

Gênero discursivo é uma forma de manifestação do discurso em uma situação sociocomunicativa determinada, em sua configuração discursiva real; já a produção de um texto em uma Prova de Redação de Vestibular, com todas as condições de produção pré-estabelecidas pelo comando, demarca uma produção escrita fora de seu contexto natural, é uma situação ressignificada, permeada por processos avaliativos.

O suporte textual especifica o projeto de dizer por meio da produção de texto, mostrando e possibilitando a materialização desse projeto. A situação da Prova de Redação do CV tem como suporte textual o espaço do caderno de provas designado como "Versão Definitiva", que acompanha, sequencialmente, a Prova de Redação. Em situações sociocomunicativas de produção textual, é por meio do gênero escolhido e próprio de cada enunciação que se define o suporte textual em que o texto é materializado. A exceção no CV acontece, justamente, pela situação hipotética, cujo objetivo é uma avaliação e seleção de candidatos a uma vaga no Ensino Superior. Com base no suporte, a circulação social é imposta, ou seja, por qual meio o texto produzido chega aos interlocutores já estabelecidos na situação de produção. Assim, a circulação social corresponde aos espaços pelos quais o texto circula. No caso do $\mathrm{CV}$, há que se considerar que a circulação efetiva ocorre, na prática, entre os avaliadores da prova, novamente, ratificando 
a situação hipotética de enunciação da escrita em que se dá a Prova de Redação de um Vestibular.

A posição do autor, como afirma Menegassi (2011, p. 108), “[...] é definida através de marcas linguístico-discursivas expressas no texto produzido", ou seja, o autor posiciona-se sócio, histórica, cultural e ideologicamente, tendo condições de assumir-se como autor de seu próprio discurso. Em situações de escrita nas quais as CPs são estabelecidas, a posição social da qual o sujeito enuncia é definida na proposta de produção, a partir dos demais elementos estabelecidos. Observa-se, no entanto, também conforme Menegassi (2011), que alguns gêneros, especialmente, os do campo escolar e acadêmico, podem indicar implicitamente a posição social, pelo fato de corresponderem a espaços sociais já definidos e conhecidos.

Por último, consideramos as estratégias do dizer como aspecto que pode ser delimitado em uma proposta de escrita, de acordo com Costa-Hübes (2012). Para a autora, as estratégias correspondem a um elemento fundamental nos comandos de produção, inclusive, de Provas de $\mathrm{CV}$, pois podem dar direcionamentos importantes aos alunos (e aos candidatos) para a escrita de um texto mais adequado ao contexto específico. Por outro lado, Silva (2018) expõe o ponto de vista de que o Vestibular não é o momento para "ensinar" a escrever e, por conseguinte, não seria adequado apresentar esse elemento. Entendemos o posicionamento de Silva, no entanto, devido a indicativos acerca da comum dificuldade em produção de texto, especialmente, os da ordem do argumentar, corroboramos a ideia de Costa-Hübes (2012) e ponderamos que não há interferência inadequada ao apresentar encaminhamento que estabeleça a estratégia para a escrita do texto demandado. Das duas provas em análise, a segunda - 2019/2020 - marca, no comando, as estratégias: “Para responder à pergunta, parta da interpretação dos textos de apoio e mobilize seus conhecimentos e informações a respeito do tema para sustentar 
argumentativamente sua resposta. Evite copiar trechos dos textos de apoio". No entanto, todas as Provas são constituídas pelas informações que, geralmente, são dispostas na capa ou na abertura da Prova de Redação e identificadas como "Instruções para a Redação". Sendo assim, ainda que não integrem o comando específico, por constituir parte da Prova e, então, compor o que Luz e Beloti (2018) designaram por "Encaminhamento de Produção", julgamos que, em alguma medida, as Provas de Redação dos CV da Unespar definem as estratégias para dizer.

Por meio de tais elementos propostos por Menegassi (2011) e Costa-Hübes (2012), os produtores de textos - candidatos, na situação da Prova de Redação do CV -, têm as circunstâncias estabelecidas para a produção de seu texto de forma ancorada em determinada situação enunciativa, tendo condições de enunciar de modo a cumprir seu propósito de dizer - o porquê escrever -; devidamente dirigido a seus interlocutores - para quem escrever -; de modo adequado - o como escrever -; sabendo o que - tema e conteúdo - escrever; assumindo-se como sujeito, devidamente posicionado, que enuncia seu projeto discursivo (GERALDI, 1997).

\section{PROVAS DE REDAÇÃO: CORPUS DE ANÁLISE}

Nesta seção, voltamo-nos ao objetivo deste trabalho que é o de analisar as Provas de Redação do CV da Unespar de 2018/2019 e 2019/2020, as quais, após a realização, foram divulgadas no site da Universidade e coletadas para objeto de investigação e debate. Pautados nos pressupostos teórico-metodológicos apresentados, examinamos os comandos de produção em termos de sua organização e composição, de acordo com os elementos estabelecidos por Geraldi (1997), Menegassi (2011) e Costa-Hübes (2012), acerca dos encaminhamentos e CPs estabelecidas nas propostas. 
Inicialmente, cumpre descrever a organização estrutural de nosso corpus: as Provas de Redação são apresentadas em duas folhas, sendo que na primeira constam as instruções para a Redação, contendo orientações mais estruturais, como: ler os textos de apoio; o número mínimo e máximo de linhas; a necessidade de escrever com letra legível; não fugir ao tema e nem ao gênero proposto; usar caneta azul ou preta; escrever de acordo com a variedade padrão da Língua Portuguesa; evitar copiar trechos dos textos de apoio. Ou seja, nas duas provas, a parte de instruções é semelhante, variando apenas o limite mínimo e máximo de linhas. Ambas as provas dispõem, também, de textos de apoio, que visam a contribuir para as premissas a serem atendidas pelo candidato acerca do conteúdo a ser dito, isto é, especificamente quanto ao tema estabelecido. Os aspectos formais e estruturais também constam no Manual do Candidato ${ }^{12}$, já divulgado previamente à realização do CV. Nesse manual são especificados, também, os critérios que ocasionam a nota zero na Prova de Redação e a consequente eliminação do processo: i. identificação do candidato; ii. texto escrito a lápis ou caneta com a cor da tinta diferente de azul ou preta; iii. fugir ao tema proposto; iv. não respeitar o limite mínimo e máximo de linhas estabelecido na proposta; v. a redação que for ilegível.

Para procedermos à análise do corpus, apresentamos abaixo a reprodução do comando de produção das duas edições em estudo:

12 Disponível em: <http://vestibular.unespar.edu.br/arquivos-vestibular-2019-2020/manualvestibular-da-unespar-correto.pdf/view>. Acesso em: 12 jun. 2020. 
Exemplo 1: Comando da Prova de Redação do CV 2018/2019

O Brasil está entre os paises com o maior indice de homicídios femininos: ocupa a $5^{a}$ (quinta) posição em um ranking de 83 naçöes, segundo dados do Mapa da violencla (disponivel em www.mapadaviolencia.org.br). E, segundo o estudo, "Violencia contra a mulher", a cada hora e mela, uma mulher e vitima do crime de feminicidio.

Considerando o contexto da violéncia e de assassinatos de mulheres no Brasil, produza um comentário crítico, para ser publicado em um fórum de discussao, em ambiente virtual, posicionando-se, com argumentos consistentes, a respeito das possiveis causas que respondem pelo aumento da violencia e número de assassinatos de mulheres no Brasil.

A seguir, apresentamos algumas referèncias sobre o tema proposto que poderäo auxiliá-lo na produçäo do seu comentário crítico.

Disponível em: <http://vestibular.unespar.edu.br/vestibulares-anteriores/vestibular2018-2019>. Acesso em: 12 jun. 2020.

Exemplo 2: Comando da Prova de Redação do CV 2019/2020

No Brasil, de modo geral, tornou-se comum, nos últimos tempos, de forma pública, a disseminação da ideia de que a solução para os problemas da violência encontra-se na regra do "olho por olho e dente por dente".

Como candidato a uma vaga no Ensino Superior público, que seria chamado a se posicionar a respeito de um assunto polêmico, como o abordado acima, produza uma Resposta Interpretativo-Argumentativa, entre 15 e 20 linhas, para a pergunta:

Essa naturalização da violência é algo recente na história social do país ou tem relação com a própria constituição econômica, política e social do povo brasileiro?

Para responder à pergunta, parta da interpretação dos textos de apoio e mobilize seus conhecimentos e informações a respeito do tema para sustentar argumentativamente sua resposta. Evite copiar trechos dos textos de apoio.

Disponível em: <http://vestibular.unespar.edu.br/arquivos-vestibular-2019-2020/provae-gabarito/prova-2019-final/view>. Acesso em: 12 jun. 2020.

Ao analisarmos as Provas-Comando dos CV de 2018/2019 e 2019/2020, pautamo-nos nos elementos discutidos por Menegassi (2011) e Costa-Hübes (2012). Denominamos o objeto deste estudo de Prova-Comando, com o propósito de marcar a caracterização da Prova de Redação como o Comando de Produção, ou seja, todos os elementos da Prova, já compreendidos como Encaminhamento de Produção (LUZ; BELOTI, 2018) desempenham a função de estabelecer os elementos e dar condições à produção textual do candidato, cujo objetivo principal é, nesse cenário, escrever um texto o mais adequado possível, visando ao ingresso no Ensino Superior e, a despeito de tal objetivo ou, justamente, para 
cumpri-lo, o propósito enunciativo prescinde do atendimento à finalidade, interlocutores, gênero textual, suporte, circulação e posicionamento social (MENEGASSI, 2011), tendo como apoio as estratégias marcadas para a produção (COSTA-HÜBES, 2012).

Observamos que ambas as provas delimitam todos os elementos, exceto o posicionamento do autor, que não foi demarcado na primeira prova em análise; e o interlocutor virtual, que, na segunda prova, não foi marcado explicitamente.

A finalidade, que se configura como o "projeto de dizer" de cada situação enunciativa, foi marcada nos dois comandos de produção: a) "Comentar criticamente os textos de apoio, assumindo posicionamento com argumentos sobre determinado tema" (2018/2019); b) "Responder argumentativamente à pergunta" (2019/2020). Aqui, observamos que a finalidade da produção condiz com o propósito da situação enunciativa, que é comentar criticamente e responder argumentativamente, conforme cada Prova-Comando. Desse modo, ainda que não conste, deliberadamente, como finalidade do texto, o comando expresso delineia a qual propósito, o porquê de se escrever aquele texto (para além do objetivo circunstancial do CV).

O interlocutor, considerado em suas três possibilidades, de certa forma, é estabelecido nas duas situações, conforme o Quadro 1. No entanto, na ProvaComando de 2019/2020, o interlocutor virtual é depreendido implicitamente, visto que a situação não demarca para quem, especificamente, o texto dirige-se, mas define, marcadamente, a posição social da qual o produtor deve enunciar: "Como candidato a uma vaga no Ensino Superior público", ou seja, é possível depreender que, dada toda a situação e tal definição, o interlocutor a quem se destina o texto é a própria Instituição de Ensino Superior. Quanto ao entendimento acerca do interlocutor real, nas duas Provas, corresponde ao professor. Segundo Silva (2018, p. 90), “[...] o interlocutor real e o superior sempre são os mesmos na situação de Vestibular: a banca avaliadora da redação e a 
Instituição de Ensino Superior responsável pela prova, respectivamente". Ponderamos que o (re)conhecimento dos papéis que os interlocutores desempenham tem caráter fundante à escrita do texto, também, porque define o gênero a ser escrito e, ao considerar o outro, a quem seu discurso é produzido, o sujeito que enuncia tem oportunidade de recuperar as possíveis imagens, em termos de expectativas, que seu interlocutor tem do tema a ser tratado, por exemplo.

O gênero refere-se ao Comentário Crítico e à Resposta InterpretativoArgumentativa, devidamente marcado nas duas Provas-Comando. Conforme já afirmamos, concordamos com Silva (2018), ao compreendermos, na situação de Vestibular, a produção de gênero textual, dado o fato de não cumprir, efetivamente, uma finalidade sociocomunicativa em situação social de interação verbal. Fossey (2019), na discussão desse aspecto no Vestibular da Unicamp, afirma:

As teorias dos gêneros, nas suas mais diversas vertentes, assumem, de forma mais ou menos consensual, que todo enunciado obedece a restrições impostas pelo gênero, no qual ele, necessariamente, se inscreve. Dessa perspectiva, assume-se também o caráter essencialmente social dos gêneros, na medida em que as práticas verbais estão sempre vinculadas às práticas da vida cotidiana de uma determinada sociedade. (FOSSEY, 2019, p. 60)

Ou seja, ainda que haja diferentes vertentes, o conceito de gênero remete à ideia de um texto que segue um "modelo" de certa forma marcado socialmente, com vistas a cumprir determinados propósitos sociocomunicativos em situação de interação verbal social. Portanto, nos exemplos em análise, os gêneros Comentário Crítico e Resposta Interpretativo-Argumentativa servem, também, para orientar a finalidade da produção textual nas respectivas Provas-Comando, recuperando, ao serem estabelecidos, todos os aspectos que os constituem - estilo de linguagem, conteúdo temático e organização composicional (BAKHTIN, [1979] 1999). 
A temática, explicitamente marcada, inclusive com destaque negrito na Prova de 2019/2020, corresponde a "Violência e assassinatos de mulheres no Brasil" e "Naturalização da violência". Além dos próprios comandos, cada tema é apresentado e discutido nos textos de apoio que integram as Provas, indicando, ainda, posicionamentos e argumentos que podem ser assumidos e/ou negados pelos candidatos. Notamos que, diferente da tradição comum em relação à prova de redação de vestibulares, o tema, nas propostas da Unespar, não precisa ser depreendido pelo candidato, ao contrário, é marcado pelo encaminhamento de produção em cada Prova. No manual do candidato, consta que o objetivo dessa Prova é "[...] avaliar a capacidade de compreensão de textos e de produção escrita" (UNESPAR, 2019, p. 33). Nesse sentido, ainda que o candidato não seja requerido a depreender o tema, deve apresentar em seu texto o adequado atendimento a esse aspecto, sem fugir do delineamento dado pelos textos de apoio, visto que fugir ao tema ocasiona a eliminação do processo.

O suporte textual apresenta-se como: a) site do fórum de discussão (ProvaComando de 2018/2019), compreendido, nesse caso, como um suporte hipotético, já que, na prática, o suporte é a própria folha da Prova, com a delimitação de linhas estabelecida; b) a folha de prova, com a delimitação entre 17 e 20 linhas (Prova-Comando de 2019/2020). A circulação social foi marcada em ambiente virtual e Concurso Vestibular, respectivamente. No segundo objeto em estudo, a circulação não é explicitamente marcada, mas captada pelos elementos que compõem o comando de produção.

O posicionamento do autor não foi marcado na primeira Prova e, na segunda, sim: "Candidato a uma vaga no Ensino Superior Público". Nesse aspecto, é importante considerar que, na prática efetiva de produção textual na situação de $\mathrm{CV}$, em todas as provas, independente do posicionamento marcado para o candidato assumir na escrita de determinado texto, ele enuncia do ponto de vista de quem deseja atender adequadamente a todos os elementos das CPs, 
a fim de atingir uma nota suficiente para o ingresso no Ensino Superior. Assim, avaliamos que, ao optar por essa delimitação no cenário de 2019/2020, a Instituição busca tratar essa Prova e, consequentemente, seus produtores como sujeitos que, efetivamente, nessa situação enunciativa, falam da posição de "Candidatos a uma vaga no Ensino Superior Público". A reflexão que pode suscitar desse aspecto é, por exemplo, quanto às práticas de escrita nos espaços escolares, as quais, comumente, também culminam na função de cumprir o conteúdo programático e/ou avaliar determinada atividade, correspondendo às concepções de escrita vinculadas às perspectivas tradicional e estrutural de ensino de Língua Portuguesa, isto é, escrita como dom, com foco na língua e/ou como consequência (SERCUNDES, 2004; MENEGASSI, 2010).

Por fim, as estratégias para o dizer (COSTA-HÜBES, 2012), em ambas as Provas, são apresentadas na primeira parte de "Instruções para a Redação" e, depois, no próprio Encaminhamento, caracterizando-se, portanto, de modo explícito e repetido. Podemos compreender, ainda, que alguns itens das "Instruções" correspondem às estratégias, ainda que tenham sido apresentados desde o Manual do Candidato, por exemplo: “Não fuja ao tema e aos gêneros propostos" e "Escreva conforme a variedade padrão escrita da Língua Portuguesa".

A seguir, apresentamos o Quadro 2, que sintetiza os elementos das CPs estabelecidos nas Provas-Comando em estudo: 
Quadro 2: Síntese dos elementos das CPs em cada Prova-Comando

\begin{tabular}{|c|c|c|c|}
\hline \multicolumn{2}{|c|}{ Elemento } & $2018 / 2019$ & $2019 / 2020$ \\
\hline \multicolumn{2}{|c|}{ Finalidade } & $\begin{array}{l}\text { Comentar criticamente os textos de } \\
\text { apoio, assumindo posicionamento } \\
\text { com argumentos sobre } \\
\text { determinado tema. }\end{array}$ & $\begin{array}{l}\text { Responder, } \\
\text { argumentativamente, } \\
\text { pergunta. }\end{array}$ \\
\hline \multirow{3}{*}{ Interlocutor } & Real & Professor. & Professor. \\
\hline & Virtual & Internautas do fórum de discussão. & $\begin{array}{l}\text { A própria instituição } \\
\text { (implícito). }\end{array}$ \\
\hline & Superior & Instituição. & Instituição. \\
\hline \multicolumn{2}{|c|}{ Gênero Discursivo } & Comentário Crítico. & $\begin{array}{l}\text { Resposta Interpretativo- } \\
\text { Argumentativa. }\end{array}$ \\
\hline \multicolumn{2}{|c|}{ Suporte Textual } & $\begin{array}{l}\text { a) Site de fórum de discussões; } \\
\text { b) Delimitação de linhas: de } 15 \text { a } 20 \\
\text { linhas em papel disponibilizado na } \\
\text { prova. }\end{array}$ & $\begin{array}{l}\text { Entre } 15 \text { e } 20 \text { linhas em papel } \\
\text { disponibilizado na prova. }\end{array}$ \\
\hline \multicolumn{2}{|c|}{ Circulação Social } & Ambiente virtual. & Concurso Vestibular. \\
\hline \multicolumn{2}{|c|}{$\begin{array}{l}\text { Posicionamento Social } \\
\text { do Autor }\end{array}$} & Não marcado. & $\begin{array}{l}\text { Candidato a uma vaga no } \\
\text { Ensino Superior Público. }\end{array}$ \\
\hline \multicolumn{2}{|c|}{ Estratégias } & $\begin{array}{l}\text { Não apresentadas no Comando, } \\
\text { mas constantes na parte inicial de } \\
\text { "Instruções para a Redação". }\end{array}$ & $\begin{array}{l}\text { Para responder à pergunta, } \\
\text { parta da interpretação dos } \\
\text { textos de apoio e mobilize seus } \\
\text { conhecimentos e informações a } \\
\text { respeito do tema para sustentar } \\
\text { argumentativamente sua } \\
\text { resposta. Evite copiar trechos } \\
\text { dos textos de apoio. }\end{array}$ \\
\hline
\end{tabular}

Fonte: Elaborado pelas autoras.

Todos esses elementos mostram-nos uma concepção de produção de texto que entende a linguagem como prática discursiva, pois para o sujeito-candidato dizer algo em sua produção é necessário que tenha, inicialmente, um motivo para fazê-lo, além das demais definições que pautam seu projeto de dizer, a fim de escrever adequadamente à situação enunciativa estabelecida, ainda que se trate de um cenário hipotético, com objetivo de avaliação, como é o CV. 


\section{CONSIDERAÇÕES FINAIS}

De acordo com o objetivo principal apresentado, os resultados indicam que as Provas de Redação dos CV da Unespar atendem às proposições do viés teórico-metodológico da Linguística Aplicada, no que se refere à organização de um comando de produção textual (GERALDI, 1997; MENEGASSI, 2011; COSTAHÜBES, 2012), de vertente enunciativo-discursiva, que compreende a linguagem como prática discursiva que possibilita a interação entre sujeitos sociais, históricos, culturais e ideológicos, que se constituem na linguagem e por ela, e se marcam em seus textos, cujo propósito é atender à finalidade discursiva de cada situação enunciativa apresentada.

O posicionamento da Instituição em relação às Provas de Redação revela um conhecimento das orientações dos documentos oficiais, atualmente vigentes, para o ensino de Língua Portuguesa e pauta-se nesta concepção que é apresentada, de que o texto é um processo que materializa a interação na enunciação, visto que, implícita ou explicitamente, estabelece os elementos das CPs, apresentando uma situação enunciativa para a escrita do texto, ou seja, ainda que hipoteticamente, dadas as reais condições de uma ocasião avaliativa e seletiva, como é o CV. De acordo com Beloti (2016), há dois aspectos que caracterizam a escrita como trabalho (FIAD; MAYRINK-SABINSON, 1991; MENEGASSI, 2016): o desenvolvimento em etapas e o delineamento das condições para a produção. As etapas, no ínterim do corpus de análise, não são passíveis de realização. Já as condições podem e, conforme apresentamos, são estabelecidas nas Provas-Comando, o que assevera o aporte na tese de que a língua/linguagem funciona, significa, de fato, segundo as determinações da enunciação (BAKHTIN, [1979] 1999; VOLÓCHINOV, 2018; 2019). Além disso, a definição de temas, relativamente em pauta na sociedade brasileira, é, também, uma forma de convocar o sujeito, neste ato, na posição real e principal de 
candidato a uma vaga no Ensino Superior público, a refletir e a posicionar-se acerca das temáticas abordadas.

No que cabe à relação com a Educação Básica, a pesquisa indica que, ao apresentar Provas de Redação assim constituídas, a Unespar marca seu diálogo com a perspectiva enunciativo-discursiva de linguagem, que subsidia o conceito de escrita como trabalho, vertentes que, além de integrarem documentos oficiais, pressupõem-se como norteadoras de práticas pedagógicas em espaços de ensino e aprendizagem de Língua Portuguesa. Logo, além de demonstrar tal aporte, também sugere um norte a estudos e práticas discursivas de escrita que, em alguma medida, objetivem tal contexto de CV.

\section{REFERÊNCIAS}

BAKHTIN, M. A estética da criação verbal. São Paulo: Martins Fontes, [1979] 1999.

BELOTI, A. A formação teórica, metodológica e prática dos conceitos de revisão e reescrita no PIBID de língua portuguesa. 2016. 227 f. Tese (Doutorado) - Programa de Pós-Graduação em Letras, Universidade Estadual de Maringá, Maringá, 2016.

BELOTI, A.; LUZ, C. da S. Práticas de escrita em contexto de Concurso Vestibular: a atuação de candidatos na prova de redação. Signo, v. 44, n. 80, p. 191-203, maio-ago. 2019. BRASIL. Parâmetros Curriculares Nacionais (PCN). Introdução. Ensino Fundamental. Terceiro e quarto ciclos. Brasília: MEC/SEF, 1998.

BRASIL. Base Nacional Comum Curricular. Brasília: MEC, 2017.

COSTA-HÜBES, T. C. Reflexões sobre os encaminhamentos de produção textual: enunciados em diálogo com outros enunciados. In: Encontro do CELSUL - Círculo de Estudos Linguísticos do Sul, 2012, Cascavel. Anais... Cascavel: UNIOESTE, 2012, p. 1-15.

FIAD, R. S., MAYRINK-SABINSON, M. L. T. A escrita como trabalho. In: MARTINS, M. H. (Org.). Questões de linguagem. São Paulo: Contexto, 1991, p. 54-63.

FOSSEY, M. Gêneros do discurso e interlocução: situando a produção escrita. In: MENDONÇA, M.; NEVES, C. A. de B. (Orgs.). A redação no vestibular Unicamp: o que e como se avalia. Campinas, SP: Editora da Unicamp, 2019, p. 57-83.

GERALDI, J. W. Portos de passagem. 2. ed. São Paulo: Martins Fontes, 1997.

LUZ, C. S.; BELOTI, A. As condições de produção na prova de redação do Concurso Vestibular da UNESPAR. Miguilim - Revista Eletrônica do Netlli, Crato, v. 7, n. 1, p. 114132, jan.-abr. 2018. 
MENEGASSI, R. J. Professor e escrita: a construção de comandos de produção de textos. Trabalhos em Linguística Aplicada, Campinas, n. 42, p. 55-79, jul./dez. 2003.

MENEGASSI, R. J. O processo de produção textual. In: SANTOS, A. R. dos; GRECO, E. A.; GUIMARÃES, T. B (Orgs.). A produção textual e o ensino. Maringá: Eduem, 2010, p. 75102.

MENEGASSI, R. J. Conceitos bakhtinianos na prova de redação. Línguas \& Letras, Cascavel, v. 12, n. 23/Especial - IX CELLIP, p. 251-276, jan.-jun. 2011.

MENEGASSI, R. J. A escrita como trabalho em sala de aula. In: JORDÃO, C. M. (Org.). A linguística aplicada no Brasil: rumos e passagens. Campinas, SP: Pontes Editores, 2016, p. 193-230.

MENEGASSI, R. J.; FUZA; A. F. A finalidade da escrita no livro didático: influências da imagem do interlocutor. Acta Scientiarum Human and Social Sciences. Maringá, v. 28, n. 2, 2006.

PARANÁ, Secretaria de Estado da Educação. Diretrizes Curriculares da Educação Básica: Lingua Portuguesa. Curitiba: SEED, 2008.

PERFEITO, A. M. Concepções de linguagem, teorias subjacentes e ensino de língua portuguesa. In: RITTER, L. C. R.; SANTOS, A. R. (Orgs.). Concepções de linguagem e ensino de língua portuguesa. Maringá: Eduem, 2010, p. 27-79 (Coleção formação de professores EAD, n. 18).

SERCUNDES, M. M. I. Ensinando a escrever. In: CHIAPPINI, L. (Coord.). Aprender e ensinar com textos. 6. ed. São Paulo: Cortez, 2004, p. 75-97.

SILVA, C. C. Caracterização dos Comandos de produção textual da prova de redação da UEM. 2018. (Dissertação) - Programa de Pós-Graduação em Letras, Universidade Estadual de Maringá, Maringá, 2018.

STELLA, P. R. Palavra. In: BRAIT, B. (Org.). Bakhtin: conceitos-chave. 5. ed. São Paulo: Contexto, 2012, p. 177-190.

UNESPAR. Manual do candidato: Vestibular 2019. Disponível em: $<$ http://vestibular.unespar.edu.br/arquivos-vestibular-2019-2020/manual-vestibular-daunespar-correto.pdf/view>. Acesso em: 12 jun. 2020.

VOLÓCHINOV, V. N. Marxismo e filosofia da linguagem: problemas fundamentais do método sociológico na ciência da linguagem. Trad. Sheila Grillo e Ekaterina Vólkova Américo. 2. ed. São Paulo: Editora 34, 2018.

VOLÓCHINOV, V. N. A palavra na vida e a palavra na poesia: ensaios, artigos, resenhas e poemas. Tradução de Sheila Grillo e Ekaterina Vólvoka Américo. São Paulo: Editora 34, 2019.

ZANINI, M. Uma visão panorâmica da teoria e da prática do ensino de língua materna. Acta Scientiarum, 21(1), Maringá, 1999, p. 79-88.

Nota do editor:

Artigo submetido para avaliação em: 12 de setembro de 2020.

Aprovado em sistema duplo cego em: 23 de fevereiro de 2021. 